\title{
Universal Service Systems for Scalable Copper Packaging of Discrete Circuit Components
}

\author{
Shuh-Ping $\mathrm{Sun}^{1}$, Jerry $\mathrm{Hu}^{2}$ \\ ${ }^{1}$ I-Shou University, Kaohsiung, TAIWAN \\ ${ }^{2}$ Ampkel Technology Ltd., TAIWAN \\ Email: 1'spsun@isu.edu.tw, ${ }^{2}$ jerryhu1226@gmail.com
}

Received: May 18, 2021. Received: November 1, 2021. Accepted: November 22, 2021. Published: December 9, 2021.

\begin{abstract}
In the decade of digital electronics, no matter what type is, high-value, high-complexity, high-performance devices (such as the main microprocessor core in smart phones) is undoubtedly crucial. However, simple discrete circuit components (such as capacitors, resistors, diodes, transistors, etc.) are also essential for mobile phones. In order to continue to increase functionality and reliability, reduce size and power consumption, reduce costs, and any function we seek in electronic equipment, there is always the basic principle of squeezing everything onto the same semiconductor chip. However, in some unavoidable situations, not all circuit components can run on the same chip. This service system uses a copper substrate as the core material for packaging, and can package chips with high bonding density. It provides a universal service platform for packaged products called: Scalable Universal Copper-based Packaging (CopperPak) service system. This service system is attributed to copper-based packaging (CopperPak) as a solution for expansion packaging, which can package the chip on the multifunctional component as much as possible. Scalable universal copper-based packaging (CopperPak) service system, including miniature copper-based packaging (TyniCopk) and large-scale copper-based packaging (MassyCopk) modules, used to package discrete circuit components, not only solve the discrete circuit components size, heat transfer and positioning alignment issues, and simplify the packaging process and improve yield rate.
\end{abstract}

Keywords-Universal Service Systems, Scalable Packaging, Copper Pak, Discrete Circuit Component

\section{INTRODUCTION}

\section{A. What is copper-based packaging (CopperPak)?}

High-complexity digital electronic devices and basic discrete components can work together as a whole in each electronic system to provide the designed system functions. A CPU failure on the motherboard certainly means that the computer is damaged. But a failure of the power rectifier diode in the power supply will also shut down the computer. For example, the diode used in the power rectifier circuit should not be on the same semiconductor as a microprocessor, and it does not match at all. Similarly, it is best to install electrostatic discharge (ESD) protection components (basically diode-based devices) closer to the microprocessor that they are designed to protect. Therefore, it is unattractive, and in many cases so small that it can hardly be recognized by the naked eye, all discrete components must operate according to the designed performance for the entire system to function properly. Figure 1 is a picture showing some of these strict discrete circuit components next to the main star IC on the circuit board of a cell phone handset. Due to smart phone becomes thinner and lighter, the small size with better withstands basic current ICs or diodes are needed integrated into the discrete circuit as shown in figure 1.

The core semiconductors of all electronic devices, whether they are complex ICs or simple diodes, require proper packaging [1], [2] in discrete circuit components as shown in figure 1. Take diodes as an example. The functional core of the diode manufactured on the semiconductor chip is cut from the production chip and encapsulated in a protective package to prevent all elements in the normal use environment of the diode. The core needs to be sealed. Except for the two electrical terminals, all surfaces of the core wire must be electrically insulated [3]. Moreover, the magnetic core also needs to dissipate the heat generated during normal operation [4], [5] while sealing it in a protective package. Under all these requirements, CopperPak is a unique technology used in electronic device packaging, and is developed with performance and reliability in mind. This technology is based on a simple principle, that is, copper (which is the best and best material in terms of electrical and thermal conductivity) is used as the core material for packaging. 
Due to the use of copper substrates as the core material for packaging, CopperPak allows the construction of high-performance device packages such as electrostatic discharge (ESD) protection diodes, transient voltage (TVS) suppressor diodes and rectifier diodes [6], [7]. It is possible to build ESD diodes packaged in CopperPak. ESD can withstand the basic current better than its competitors, so as to better protect its host system. Similarly, CopperPak power diodes can handle larger currents, thus providing higher power ratings than their competitors.

\section{B. Principal applications of CopperPak}

The principal applications of copper-based packaging (CopperPak) include power diodes/rectifiers, TVS and ESD protection devices. These devices are classified in the industry as powering discrete circuit components. At the same time, CopperPak is also suitable for non-powered discrete components, such as resistors and capacitors. Discrete circuit components are essential for building various digital or analog electronic systems, and CopperPak as a useful packaging technology is also applicable to other components.

The proprietary packaging design and manufacturing technology behind CopperPak has led to the rapid miniaturization of discrete circuit components, reducing the size to 01005 and below. It is expected to be feasible in the future 0050025 sizes, or the slightly large scale 0070035 size, especially among manufacturers of non-powered resistors and capacitors. At present, JEDEC 0050025 (or even large scale 0070035) products are still in the development stage, and the parallel development of pick-and-place automatic equipment required for the assembly of "miniaturized" such components is yet to be assembled. However, this service system (CopperPak)'s TyniCopk is ready for the basic structure design of the 0050025 miniature package technology.
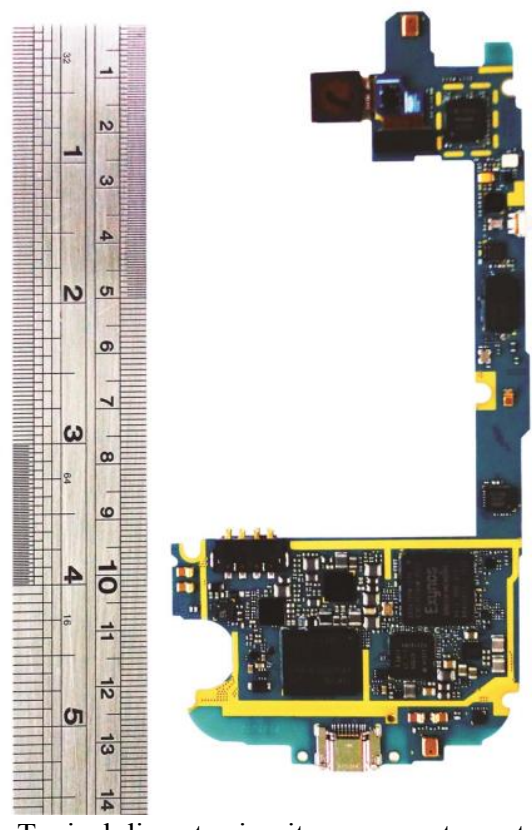

Figure 1. Typical discrete circuit components next to the main processor IC on the mobile phone circuit board.

\section{METHOD}

The Scalable Universal Copper-based Packaging (CopperPak) service system references the engineering philosophy of $\mathrm{Cu}$ lead frame packaging technology. Based on the principle of copper-based packaging (CopperPak), from the perspective of material selection, copper is the material that ensures the best electrical and thermal performance of device packaging. Of course, other materials (such as gold) can also provide better characteristics (such as conductivity), but factors including cost hinder its use in mass-produced products. In addition to material selection, there is also the problem of establishing appropriate production methods. Taking into account the use of materials and mass production process, CopperPak can meet the basic design concept of packaging components with the best electrical and thermal performance guidelines.

First of all, copper is the main material that constitutes CopperPak's "encapsulation base material", and is actually the only material. Copper in sheet form with sufficient thickness is not only used as a substrate in the production stage, but also as the final electrical conductor of CopperPak components. Obviously, the use of copper alone and copper alone has important benefits, which can obtain the best electrical and thermal conductivity for the structure of CopperPak discrete circuit components. More importantly, the use of a single copper means that if multiple materials are used in the construction of the package, there is no need to compromise between a complex and inevitable set of conflicting processing conditions.

The in operation packaging process carry out the following procedures in order:

$\checkmark$ Substrate (Placement)

Place Dice (Placement)

- Wire Bonding (Wire Bonding)

$\checkmark$ Mold Compound (Mold Compound)

$\checkmark$ Cutting the sealing chip (Dicing)

The meta-model architecture of Scalable Universal Copper-based Packaging (CopperPak) service system descripted in Figure 2.

\begin{tabular}{|c|c|c|c|c|}
\hline Meta Model layer & \multicolumn{4}{|c|}{$\begin{array}{l}\text { The Scalable Universal Copper-based Packaging } \\
\text { (CopperPak) service system } \\
\text { High Performance Discrete Circuit Components } \\
\text { Packaging }\end{array}$} \\
\hline Model layer & \multicolumn{2}{|c|}{$\begin{array}{c}\text { miniature copper-based } \\
\text { packaging } \\
\text { (TyniCopk) }\end{array}$} & \multicolumn{2}{|c|}{$\begin{array}{l}\text { large-scale copper-based } \\
\text { packaging } \\
\text { (MassyCopk) }\end{array}$} \\
\hline \multirow{3}{*}{$\begin{array}{l}\text { Information layer } \\
\text { (Stage I) }\end{array}$} & Configure & Dice & Silver Paste & AU Wire \\
\hline & $\begin{array}{c}\text { copper } \\
\text { substrate }\end{array}$ & & & (Epoxy Insulating) \\
\hline & \multicolumn{4}{|c|}{ Mold Compound } \\
\hline $\begin{array}{c}\text { Information layer } \\
\text { (Stage II) }\end{array}$ & \multicolumn{4}{|c|}{$\begin{array}{l}\text { Termination } \\
\text { (Marking, Cutting, Cleaning, Testing) }\end{array}$} \\
\hline
\end{tabular}

Figure 2. Meta-model of the Scalable Universal Copper-based Packaging (CopperPak) service system 
Meta-model of the scalable universal copper-based packaging service system (Fig.2) contains a miniature copper-based package (TyniCopk) and a large scale copper-based package (MassyCopk) module. Each module contains two stages and five steps. In the first stage, four steps are performed: a copper substrate (Substrate) is configured on the upper and lower metal layers of the chip (Dice); when the copper substrate is in position, the chip metal layer adhesive is mounted on the copper substrate with conductive silver paste (Silver Paste); Insulating glue (Epoxy) is injected between the substrates into the AU Wire process, and the copper-based package (CopperPak) chip encapsulation and molding (Mold Compound) are also completed. In stage two, one step is performed: the step of termination the molding chip (marking, cutting, cleaning, testing). Finally, the semiconductor package is completed. The process flow of the Scalable Universal Copper-based Packaging (CopperPak) derive from Meta-model (Fig. 2) can show on Fig.3.

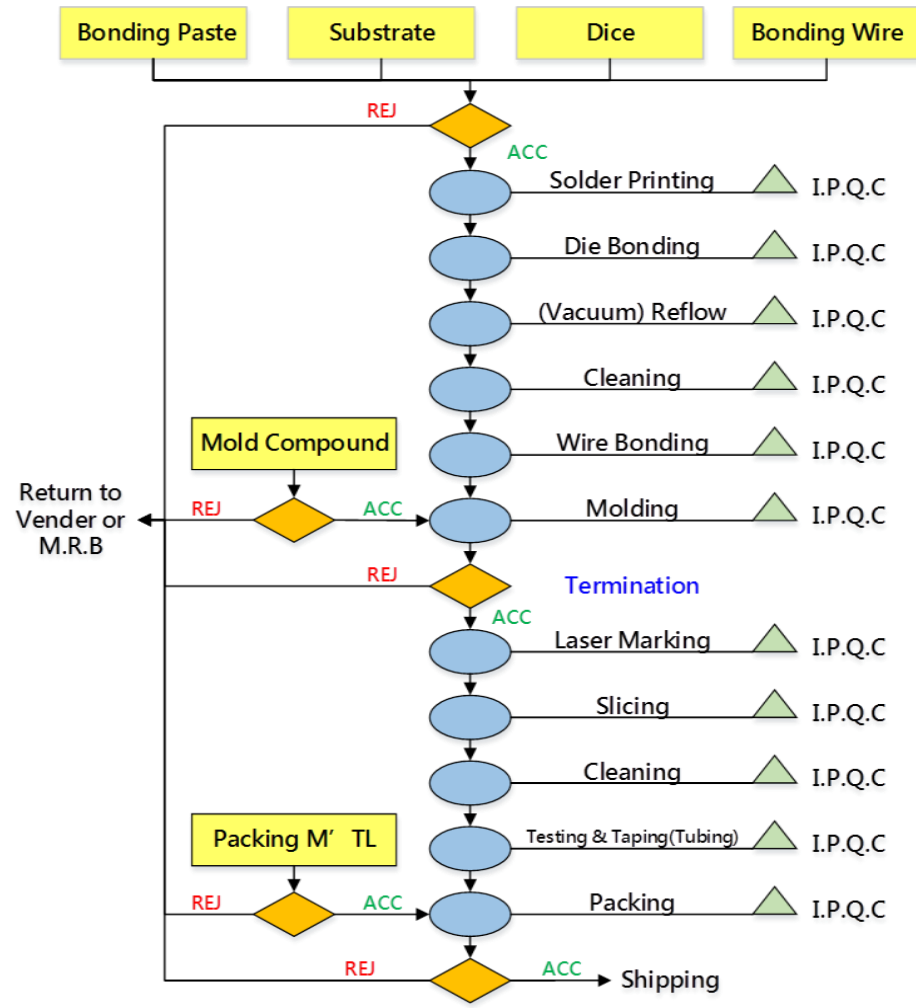

Figure 3. Scalable Universal Copper-based Packaging (CopperPak) Process

Comparing the scalable universal copper-based packaging service system with the in operation packaging process, the copper-based packaging (CopperPak) service system solves the problems of packaging component size, heat transfer and positioning alignment, simplifies the packaging process, reduces production costs, and improves the non-defective rate.

\section{RESULTS}

The Scalable Universal Copper-Based Packaging (CopperPak) service system is particularly suitable for packaging discrete circuit components, such as simple two-terminal powered diodes or non-powered capacitors. Although its TyniCopk packaging product line is suitable for packaging the smallest JEDEC 01005 and smaller small equipment (such as the equipment provided by the scalable universal copper-based packaging service system TyniCopk product line), the scalable universal copper-based packaging service system is also suitable for packaging large equipment. Power diodes are produced in the MassyCopk product line of the extensible universal copper-based packaging service system. The power diodes meet military standards and have the same quality as JEDEC TO-268. This power diode produced in the MassyCopk product line has a proprietary electrical terminal size, which ensures increased conductivity to match its rated power.

The scalable universal copper-based packaging service system is also suitable for packaging equipment with more than two terminals. It is possible to package devices that are basically arrays or circuits with multiple two-terminal diodes than diodes. Figure 2 is a meta-model diagram showing a scalable universal copper-based packaging service system. The Universal CppperPak Service System Process (Fig. 3) implement by Ampkel Technology Ltd., TW shown in Figure 4(a) is the TyniCopk series of 0201 ESD equipment. Its footprint is $0.5 \mathrm{~mm} \times 0.25 \mathrm{~mm}$, the right side is 01005 , and the size is 0.25 millimeters by 0.13 millimeters. Figure $4(\mathrm{~b})$ is a picture of the products made by the miniature (TyniCopk) and large-scale (MassyCopk) modulus of the scalable universal copper-based packaging service system to understand their relative sizes. Although their sizes vary greatly, both manufacturing techniques can be derived from the Scalable Universal Copper-based Packaging (CopperPak) service system and implemented by the Ampkel Technology Ltd., TW.

The process of the Scalable Universal Copper-based Packaging (CopperPak) service system for Figure 4(a) and Figure 4(b) has a productivity of up to $98 \%$ for similar products. This is achievable only because the control of the above manufacturing conditions is easy. The simplicity of the scalable universal copper-based packaging service system is translated into the characteristics of high alignment accuracy, which is the most important factor to achieve high output. This also explains why traditional arrays, especially those that use PCBs as substrates, usually only have dozens of rows and columns. As a result, the scalable universal copper-based packaging service system has increased batch efficiency (in terms of number of product units) by 2 generations: compared to hundreds of products delivered by traditional technologies, tens of thousands per array batch product components.

In many embodiments, the Scalable Universal Copper-based Packaging (CopperPak) service system can also be used for hermetic sealing of resin and copper. The use of a mono-metal copper makes the entire process easier, so after completing most or all of the necessary copper processing steps, the resin can be easily applied in the final stage.

The scalable universal copper-based packaging (CopperPak) service system compares with the in operation packaging process. Copper-based packaging (CopperPak) could handle the problems of packaging component size, heat transfer and 
positioning alignment, simplifies the packaging process, reduces production costs, and improves the non-defective rate. Copper does not occur in the scalable general copper-based packaging service system.

Therefore, the ultimate benefit of using a mono-metal (copper) and simplifying the process not only helps to increase the manufacturing efficiency of scalable universal copper-based packaging (CopperPak) service system devices, but also helps reduce the cost of the device. The second criterion is to use the existing mature copper processing technology used in similar industries as much as possible, and apply to the scalable universal copper-based packaging service system. The benefits are obvious. Mature technology means fewer unexpected problems.

(a)

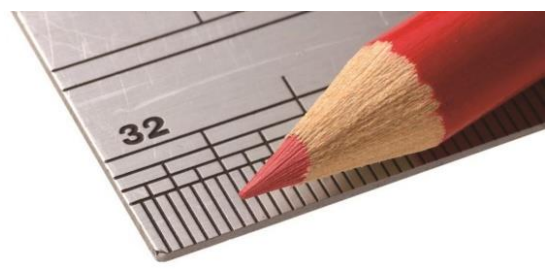

$\sum_{0201}^{=}$

(b)

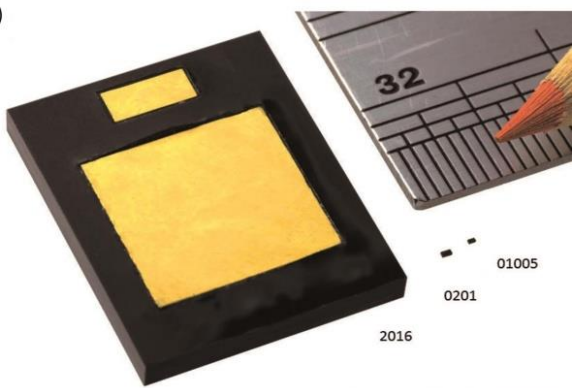

Figure 4. Scalable Universal Copper-based Packaging (CopperPak) service system (a) miniature copper-based packaging (TyniCopk) products and (b) large-scale copper-based packaging (MassyCopk) products.

\section{DISCUSSION}

\section{A. Large-scale copper-based packaging (MassyCopk)} modules

The concept of the large copper-based package (MassyCopk) module of the scalable universal copper-based package (CopperPak) service system (see Figure 2), that is, copper is the only packing substrate, and the result of the packing condition control becomes simple, which can be achieved highly efficient mass production of discrete circuit components.

Over view the scalable universal large-scale copper-based package (MassyCopk) service system modulus (as shown in Figure 5(a)), it operates in two stages:

Stage I: Configure the copper substrate (Substrate), stick the chip (Dice) to the substrate with Silver Paste, inject the insulating glue into the AU wire, and perform these four steps (Substrate, Dice, Silver Paste, AU Wire) can simultaneously complete Dice encapsulation and molding (Mold Compound), as shown in Figure 5 (b), (c).
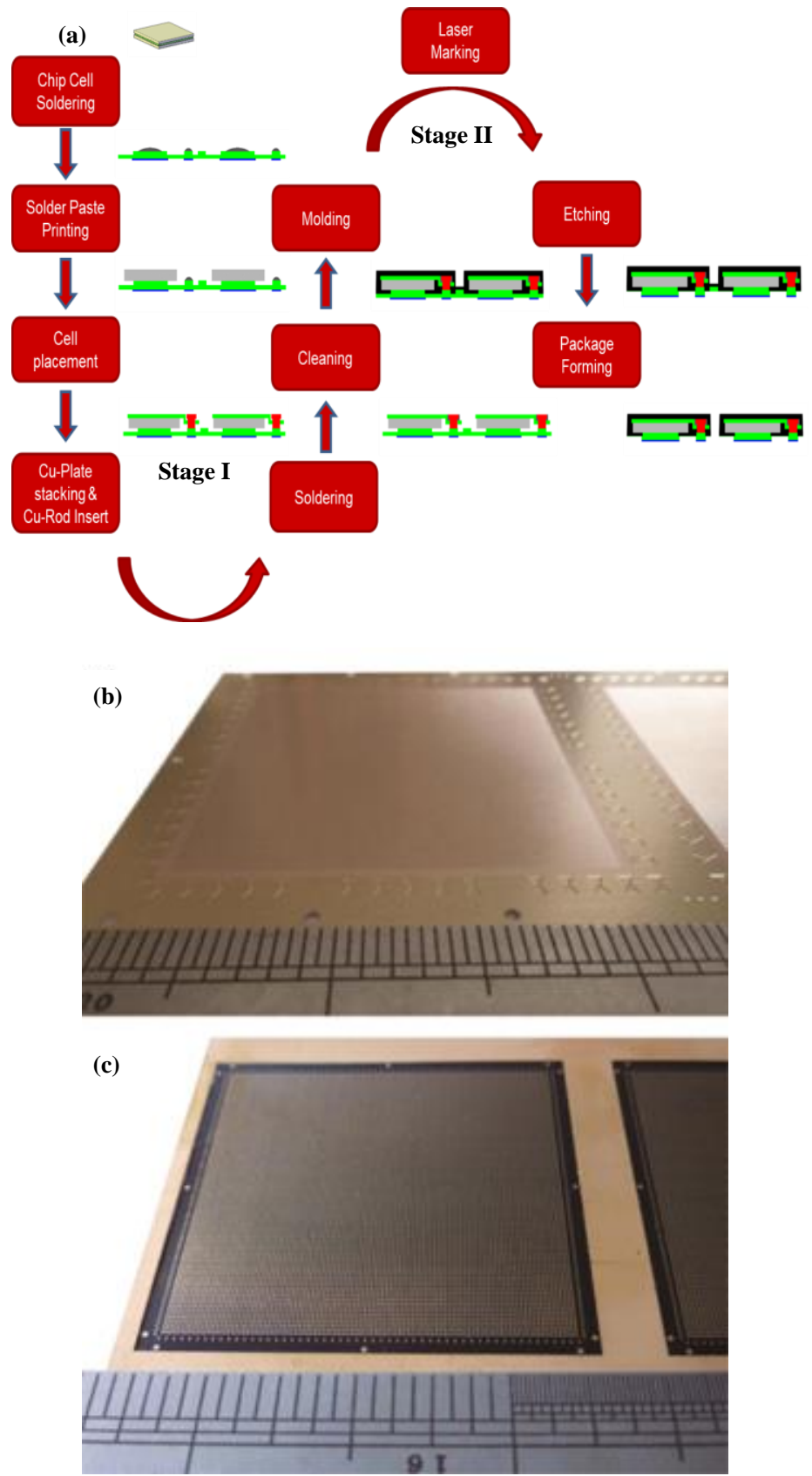

(d)

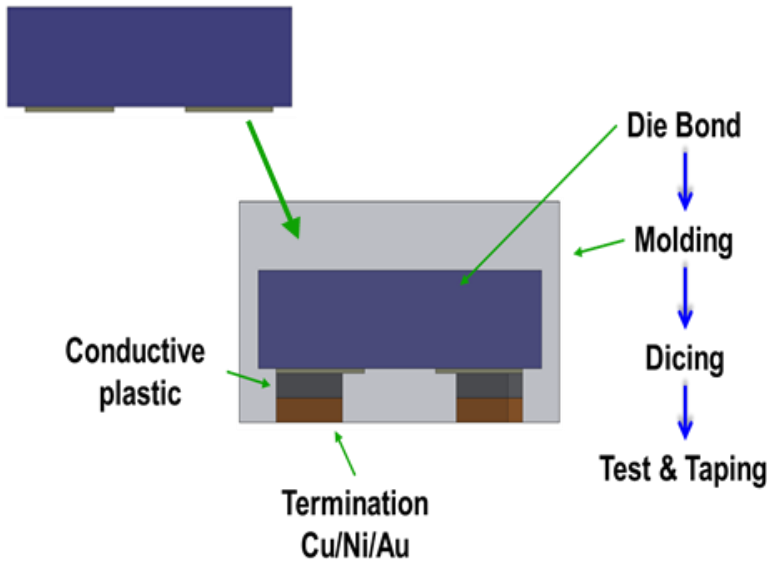




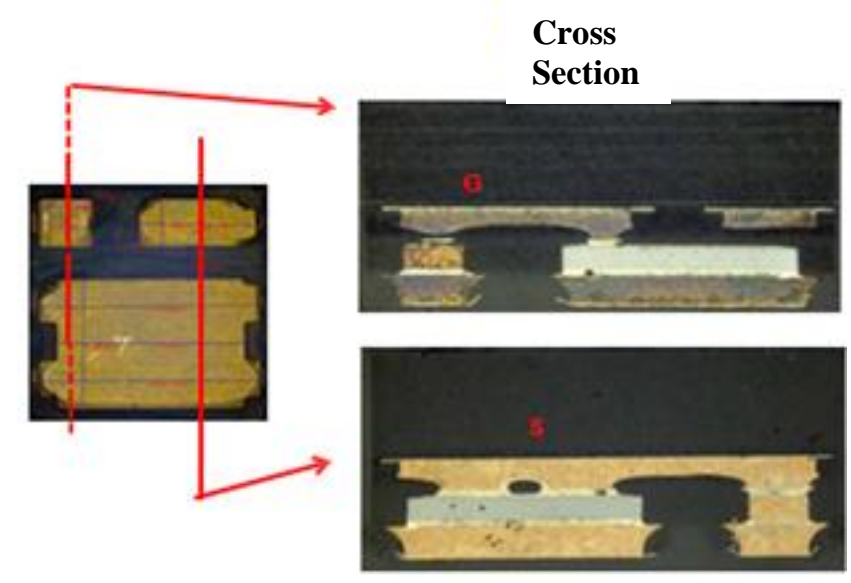

Figure 5. (a) Large-scale copper-based package (MassyCopk) process for scalable universal copper-based package service system (b) Wafer array of thin copper substrates in the production stage of MassyCopk (c) After CopperPak, wafer cut into a monolithic chip array package (d) CopperPak component array cut into a single die packing schematic

Stage II: After the encapsulation and molding (Mold Compound) chips are processed (marking, cutting, cleaning, testing) to complete the semiconductor packing, as shown in Figure 5(d). As shown in Figure 5(b), the picture of a large-scale copper-based package (MassyCopk) wafer element array before dicing. Each mass-produced device has a wafer array embedded in its substrate to produce array component products.

Figure 5(c) is a photo of a large-scale copper-based package (MassyCopk) wafer element array after cutting. It can be diced from the array to release each of thousands of individual packing element, as shown in Figure 5(d).

The Large-scale copper-based packaging (MassyCopk) module of the scalable universal copper-based package (CopperPak) service system is used to packing IC modules, which not only solves the problem of module size, heat transfer and alignment, but also simplifies the packaging process.

\section{B. Miniature copper-based packaging (TyniCopk) modules} In the TyniCopk product line implement by the scalable universal copper-based packaging (CopperPak) service system, miniaturization of components does not sacrifice performance. The package process developed by the Mini Universal Copper-based Package (TyniCopk) service module (Figure 2) implemented in this case as shown in Figure 6 significantly improves the accuracy, efficiency and highly cost savings of the in operation Lead Frame Packing process. Thus the Scalable Universal Copper-based Packaging (CopperPak) service system (Figure 2), it is actually high-performance when it examines its design methods and compares it with competitors' devices. The Scalable Universal Copper-based Packaging (CopperPak) service system transient voltage suppression device is essentially an electro-polymerized one or more avalanche breakdown diodes, and its protection capability is much higher than its traditional similar products.
The performance characteristics shown in Table I (such as the rated power of a diode) are usually proportional to their physical dimensions. Larger size diodes can withstand more current than smaller diodes. But the universal copper-based packaging (CopperPak) service system has managed to improve the product performance load voltage and current while reducing its physical size. This means that the TyniCopk DFN 0201 component can undertake the same circuit protection tasks that are usually only undertaken by the larger 0402. After testing, the TyniCopk service system of this case TyniCopk DFN 0201 component type has better protection voltage rating than typical traditional 0402 devices. Thus when compared to conventional devices of the same size, the performance of the TyniCopk service system components is much better. Compared to conventional devices with the same performance level, the TyniCopk service system components are at least one size smaller. Therefore, space is saved or performance is improved. In some cases, both are achieved at the same time some relevant studies can be found in [8], [9], [10], [11].

The performance of DFN characters are measurement by ESD gun, SKYLARK ESD-G2005, as shown in Figure 6 and Table I, the packaging process of the TyniCopk service system vs the in operation lead frame package (Lead Frame Package) packaging process has the following competitive advantages over the conventional diode die bonding packaging process:

(a) Significantly improve product accuracy tolerance from $60 \mu \mathrm{m}$ to $10 \mu \mathrm{m}$ resolution from $50 \mu \mathrm{m}$ to $30 \mu \mathrm{m}$ packaging temperature from 270 degrees Celsius to 400 degrees Celsius (b) Significantly improve product performance, load voltage and current increase by $30 \%$, cooling capacity is increased by at least $50 \%$, so service life can be doubled

(c) A substantial increase in product profit is based on a unit price of $\$ 15 / \mathrm{K}$ unit, and the profit increases from $15 \%$ to $60 \%$ (d)The chip packaging process of Figure 6 (TyniCopk), which solves the problems of circuit component size, heat transfer and positioning alignment, simplifies the packaging process, reduces production costs, and improves yield rate.

The main functions of Scalable Universal Copper-based Packaging (TyniCopk) service system products are compared with existing products/technologies. ESD devices are manufactured by many companies. In Table II, a standard ESD commercial product of series No JEDEC 0402 is selected for comparison, because the scalable universal copper-based packaging (TyniCopk) service system process implemented in this case can ensure that it is the same semiconductor core (ESDQR8V0BS).

Copper-based packaging (CopperPak) as a packaging technology involves packaging technology of discrete circuit components that are different from integrated semiconductor die. Therefore, by comparing the process products of the CopperPak service system that is extensible in the same device with the commercially available CrownPo products, Table II can truly reflect how the copper-based package (TyniCopk) can be used as a packaging technology. Its competitors make major 
improvements. The comparison in Table II clearly shows that the Scalable Universal Copper-Based Packaging (TyniCopk) service system using the same semiconductor die can build smaller JEDEC 0201 ESD components with performance even larger than the larger 0402 components in the benchmark (ESDQR8V0BS) is better. This means two things. First, with the same die, the volume efficiency of the scalable universal copper-based package (TyniCopk) service system is much higher than its competitors when "encapsulating" the die.

\section{Limitations of the service system}

The Scalable Universal Copper-based Packaging (CopperPak) service system is transcend of industry standards in miniaturized packaging. In its TyniCopk product line, miniaturized packaging technology for power-generating discrete circuit components has been prepared. It is expected that the commercial availability of small equipment such as TyniCopk will provide a huge impetus to speed up the preparation of its development work. So far, based on the limitations of existing mass production lines, there are relatively few TyniCopk packaging product lines that use this miniaturized copper-based packaging technology for the scalable universal copper-based packaging (CopperPak) service system. This is to consider technology and commercial restrictions on the mass production line.

Table 1. Comparison of the packaging process between the TyniCopk service system and the in operation Lead Frame Package

\begin{tabular}{|c|c|c|c|c|}
\hline \multirow{2}{*}{ Series } & \multicolumn{2}{|c|}{ Key Feature } & \multicolumn{2}{|c|}{ Price(profit) } \\
\hline & $\begin{array}{l}\text { TyniCopk } \\
\text { Service }\end{array}$ & $\begin{array}{l}\text { Lead Frame } \\
\text { Package }\end{array}$ & $\begin{array}{l}\text { TyniCopk } \\
\text { Service }\end{array}$ & $\begin{array}{l}\text { Lead Frame } \\
\text { Package }\end{array}$ \\
\hline $\begin{array}{l}\text { DFN } \\
0201\end{array}$ & $\begin{array}{c}\text { Tolerance } \\
<10 \mu \mathrm{m} \\
\text { Resolution } \\
<30 \mu \mathrm{m}\end{array}$ & $\begin{array}{c}\text { Tolerance }< \\
60 \mu \mathrm{m} \\
\text { Resolution }< \\
50 \mu \mathrm{m} \\
\text { Thickness }\end{array}$ & $\begin{array}{c}\begin{array}{l}\$ 8 \sim 10 / \text { K-unit } \\
(50 \% \sim 60 \%)\end{array}\end{array}$ & $\begin{array}{c}\text { \$10/K-unit } \\
(15 \%)\end{array}$ \\
\hline $\begin{array}{l}\text { DFN } \\
0402\end{array}$ & $\begin{array}{c}\text { Tolerance } \\
<10 \mu \mathrm{m} \\
\text { Resolution } \\
<30 \mu \mathrm{m} \\
\text { Thickness } \\
-30 \% \\
\text { Dimension } \\
-15 \% \\
\text { Packing } \\
\text { Temp. up } \\
\text { to } 400 \\
\text { degrees C }\end{array}$ & $\begin{array}{c}\text { Tolerance }<60 \\
\mu \mathrm{m} \\
\text { Resolution }< \\
50 \mu \mathrm{m} \\
\text { Thickness }+30 \\
\% \\
\text { Dimension } \\
+15 \% \text { Packing } \\
\text { Temperature }< \\
270 \text { degrees C }\end{array}$ & $\begin{array}{c}\$ 12 \sim 15 / \mathrm{K}-\text { un } \\
\text { it } \\
(50 \% \sim 60 \%)\end{array}$ & $\begin{array}{c}\text { \$15 20/K-unit } \\
(15 \%)\end{array}$ \\
\hline
\end{tabular}

Table 2. Comparing TyniCopk to in operation technology of ESD on the same semiconductor core

\begin{tabular}{|c|c|c|c|}
\hline & ESD Size & $\begin{array}{c}\text { TyniCopk } \\
0201 \\
\end{array}$ & $\begin{array}{c}\text { JEDEC } \\
0402 \\
\end{array}$ \\
\hline \multirow{6}{*}{ 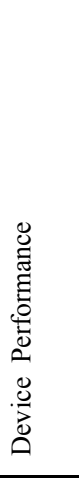 } & Type Number & $\begin{array}{l}\text { ESD5VOK7-AH- } \\
0603\end{array}$ & ESDQR8V0BS \\
\hline & $\begin{array}{lr}\text { ESD per IEC } & 61000-4-2 \\
\text { testing } & \text { standard } \\
\text { (contact) } & \\
\end{array}$ & $+/-15 \mathrm{kV}$ & $+/-12 \mathrm{kV}$ \\
\hline & $\begin{array}{lr}\text { ESD per } & \text { IEC } \\
61000-4-2 & \text { testing } \\
\text { standard (air) } & \\
\end{array}$ & $+/-25 \mathrm{kV}$ & $+/-17 \mathrm{kV}$ \\
\hline & $\begin{array}{l}\text { Peak pulse current } \\
\text { (tp } 8 / 20 \text { microsecond) }\end{array}$ & $5 \mathrm{~A}$ & $4 \mathrm{~A}$ \\
\hline & $\begin{array}{l}\text { Peak pulse power } \\
\text { (tp } 8 / 20 \text { microsecond) }\end{array}$ & $80 \mathrm{~W}$ & $100 \mathrm{~W}$ \\
\hline & Junction capacitance & $7 \mathrm{pF}$ & $7 \mathrm{pF}$ \\
\hline \multirow{3}{*}{ 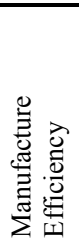 } & $\begin{array}{l}\text { Type of Production } \\
\text { Substrate }\end{array}$ & Pure copper & $\begin{array}{l}\text { Printed Circuit } \\
\text { Board }\end{array}$ \\
\hline & $\begin{array}{l}\text { Array Size on } \\
\text { Production Substrate }\end{array}$ & $\begin{array}{l}264 \text { rows by } 68 \\
\text { columns } \\
=17,952 \text { devices } \\
\end{array}$ & $\begin{array}{l}80 \text { row by } 60 \\
\text { columns } \\
=4,800 \text { device }\end{array}$ \\
\hline & Substrate Size & $140 \mathrm{~mm} \times 60 \mathrm{~mm}$ & $90 \mathrm{~mm} \times 60 \mathrm{~mm}$ \\
\hline
\end{tabular}

\section{V.CONCLUSION}

CopperPak leads ahead of industry standards with regards to miniaturization. In its TinyCopk product line, 01005 and even 0050025 active discrete circuit components are ready, while the industry is barely. It is expected that commercial availability of miniaturized devices like TinyCopk would constitute substantial driving force for assembly equipment makers, pick-and-place robots in particular, to accelerated their develop works and have their machines ready. Due to the use of copper substrates as the core material for packaging, CopperPak ESD can withstand the basic current better than its competitors, so as to better protect its host system. CopperPak power diodes can handle larger currents comparison to previous works (Table I, II), thus providing higher power ratings than their competitors. It is worth noting that the diodes used to prevent electrostatic discharge or transient voltage due to various reasons are not compatible with the resolution circuit of the performance processor to be manufactured on the device. The copper-based packaging modules, used to package discrete circuit components in this empirical study, not only solve the discrete circuit components size, heat transfer and positioning alignment issues, and simplify the packaging process. Whether it is downscaled to the smaller size of the scalable universal copper-based packaging service system TyniCopk product line, or to a larger size of the scalable universal copper-based packaging service system MassyCopk power component product line, can be extended to the universal copper-based packaging service. Yet they're indispensable even though few notice their presence in all sorts of electronic products, consumer, science and industrial equipment alike. In the coming ages here there are always occasions that additional diodes and transistors are needed outside of the circuit of a complex component. Notably diodes for protection against 
electrostatic discharge or transient voltage arising from various causes are not compatible with the nanometer-resolution circuitry of performance processors to be made on-device. The copper-based packaging (CppperPak) technology shall be solved the system configuration and implemented leads solution in scalable packaging technology.

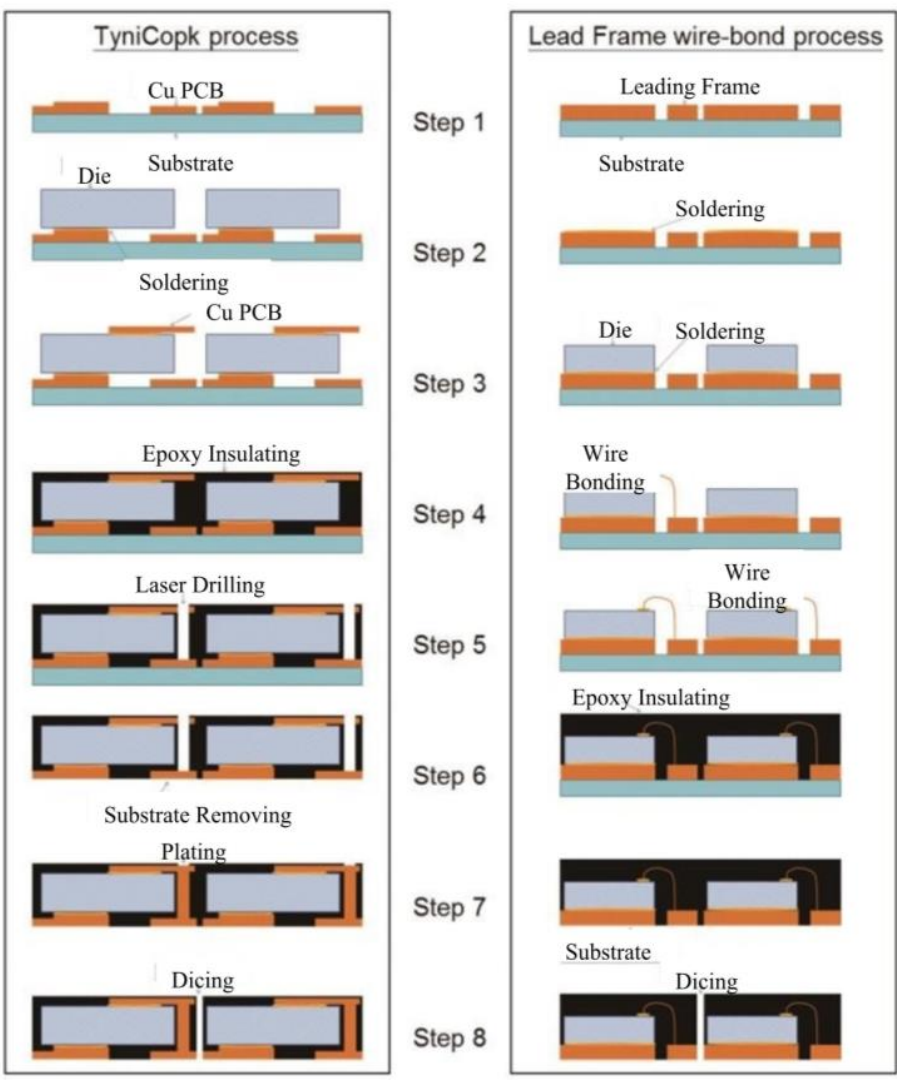

Figure 6. Miniature Universal Copper-Based Packaging (TyniCopk) Service System vs. operation Lead Frame Wire-bond process.

\section{REFERENCES}

[1] W. H. Li and S. W. Joelle Ong, "Cu diffusion in Ag-plated $\mathrm{Cu}$ lead frame packages", Mircoelectron. Reliab., vol. 52, no. 7, pp. 1523-1527, Jul. 2012.

[2] Wu-Hu Li, A. Acuesta, M. G. Mercado, N. T. Malonzo and R. S. Cabral, "Cu wire bonding in $\mathrm{Ni} / \mathrm{Pd} / \mathrm{Au}-\mathrm{Ag}$ and roughened $\mathrm{Ni} / \mathrm{Pd} / \mathrm{Au}-\mathrm{Ag}$ pre-plated leadframe packages," 2011 IEEE 13th Electronics Packaging Technology Conference, Singapore, pp. 794-797, 2011

[3] T. Y. Lin, M. G. Pecht, D. Das, J. Pan and W. Zhu, "The evaluation of copper migration during the die attach curing and second wire bonding process", IEEE Trans. Compon. Packag. Technol., vol. 28, no. 2, pp. 337-344, Jun. 2005.

[4] Razali, N., Omar, G., Esa, S.R., Jasmee, S., Kamarolzaman, A.A, "Effect of annealing temperature on the surface properties of copper-based leadframe," Journal of Advanced Research in Fluid Mechanics and Thermal Sciences , pp. 266-273, 2018.

[5] J. R. Huo, S. G. Qiang, J. Jiang, W. J. Tao and L. Wen Kong, "Advance Embedded Packaging for Power Discrete
Device," Trans. On 2019 IEEE 69th Electronic Components and Technology Conference (ECTC), pp. 1485-1491, 2019.

[6]L. Zhang et al., "Study on Ag-Plated Cu Lead Frame and Its Effect to LED Performance Under Thermal Aging," in IEEE Transactions on Device and Materials Reliability, vol. 14, no. 4, pp. 1022-1030, Dec. 2014.

[7] Ulrich, R, "Embedded resistors and capacitors for organic-based SOP" IEEE Transactions on Advanced Packaging, Volume: 27, pp.326- 331, May 2004.

[8] Kavuličová Jana, Sedláková-Kaduková Jana, Ivánová Dana, Repický Vladimír, "Responses of Linum Usitatissimum and Callistephus Chinensis on Copper Contaminated Substrate", pp. 493-499, WSEAS Transactions on Environment and Development, Volume 15, 2019

[9] Abdelkrim Moufakkir, Abderrahim Samaouali, Abdellah Elbouzidi, Salah El Alami, Abderrahim Dinane,"Thermophysical Characterization of Composite Clay Materials Doped by the Copper Powder According to the Temperature", pp. 324-329, WSEAS Transactions on Environment and Development, Volume 16, 2020

[10] Ph. Dondon, A. Szalajko, "Thermal Characterisation and 3D Virtual Modelling of a Modern Timber-frame Small Scale House", WSEAS Transactions on Environment and Development, vol. 17, pp. 201-210, 2021

[11] M. H. Roushdy, "Recycling of Cullet, Waste Clay Bricks and Wastes Resulted from Wheat and Sugarcane Cultivations in the Manufacture of Fired Clay Bricks", WSEAS Transactions on Environment and Development, vol. 17, pp. 192-200, 2021

\section{Contribution of Individual Authors to the Creation of} a Scientific Article (Ghostwriting Policy)

Shuh-Ping Sun conceived and designed the Scalable Copper Packaging Universal Service Systems Model.

Jerry Hu carried out Scalable Copper Packaging Universal Service System's experiments.

Shuh-Ping Sun and Jerry Hu wrote the paper.

\section{Creative Commons Attribution License 4.0 (Attribution 4.0 International, CC BY 4.0)}

This article is published under the terms of the Creative Commons Attribution License 4.0

https://creativecommons.org/licenses/by/4.0/deed.en_US 